\title{
GM1 Gangliosidosis
}

National Cancer Institute

\section{Source}

National Cancer Institute. GM1 Gangliosidosis. NCI Thesaurus. Code C84739.

An autosomal recessive lysosomal storage disease characterized by deficiency of the enzyme acid beta-galactosidase, resulting in the accumulation of acid lipids in the nervous system. Signs and symptoms include neurologic disturbances, muscle atrophy, dystonia, eye abnormalities, and formation of angiokeratomas. 